\title{
Fractographic analysis, accuracy of fit and impact strength of acrylic resin
}

\section{Fernanda Faot ${ }^{(a)}$ \\ Renata Cunha Matheus Rodrigues Garcia $^{(b)}$ \\ Altair Antoninha Del Bel Cury ${ }^{(b)}$}

(a) PhD student; (b)Chair Professors - Department of Prosthodontics and Periodontology, Piracicaba Dental School, State University of Campinas, Piracicaba, SP, Brazil.

\section{Corresponding author:}

Renata Cunha Matheus Rodrigues Garcia

Av. Limeira, 901

Piracicaba - SP - Brazil

CEP: 13414-903

E-mail: regarcia@fop.unicamp.br

Received for publication on Mar 26, 2007

Accepted for publication on Nov 05, 2007

\begin{abstract}
This study evaluated accuracy of fit, impact strength, types and morphology of fractures of a microwave acrylic resin polymerized with a cycle alternative to that recommended by the manufacturer. Onda Cryl was polymerized according to the manufacturer's instructions (MC), 3 $\min$ at $360 \mathrm{~W}, 4-\mathrm{min}$ pause, and $3 \mathrm{~min}$ at $810 \mathrm{~W}$; and with an alternative cycle $(\mathrm{AC})$ of $6 \mathrm{~min}$ at $630 \mathrm{~W}$. Accuracy of fit was measured at 3 points at the right $(\mathrm{A})$ and left $(\mathrm{B})$ ridge crests and at the midline $(\mathrm{C})$ on the posterior palatal seal for each denture base ( $\mathrm{n}=10$ /group). The measurements were taken immediately after finishing and after 30-day storage in water. The impact strength test (Charpy method) was performed with a $40 \mathrm{~kJ} / \mathrm{cm}$ load ( $\mathrm{n}=20 / \mathrm{group}$ ). Fractographic analysis was accomplished for all fragments and the fracture types were characterized by means of their morphology, crack propagation angles and microstructure. Accuracy of fit data were analyzed by ANOVA, impact strength and radius values were compared by the $t$ test, and the fractographic analysis data, by the Wilcoxon Mann-Whitney test. The significance level was fixed at $p<0.05$. No statistical differences were found between the two cycles of polymerization used. However, after the 30 -day storage period in water, the denture bases showed better fit $(P<.05)$. Most of the fractures were classified as brittle (MD: $70 \%$, AC: $80 \%$ ). Based on the results of this study, it could be concluded that both polymerization cycles are adequate to polymerize the denture resin studied.
\end{abstract}

Descriptors: Dental materials; Acrylic resins; Physical properties. 


\section{Introduction}

Since the introduction of acrylic resins for denture fabrication in dentistry, there has been ongoing search for improving polymerization methods. Microwave energy has been reported as one of the promising choices for dental laboratories, considering its advantages, such as being less time consuming, taking less time to reach the plastic phase, having better homogeneity of the mixture and improved accuracy of fit..$^{1-6}$

Although microwave-polymerized acrylic resins have advantages, some manufacturers indicate a pause period to avoid an excessive heating, which could be unfavorable, as it could change the work routine in a dental laboratory considering the different types of microwave oven. There are several programs that can be set for microwave ovens, ranging from those whose time and wattage can be totally programmed up to those that don't have these possibilities. Considering the use of the latter, changes in laboratory work require that technicians control the polymerization time, and this could lead to the use of arbitrary times and wattages. Moreover, the effect of a pause period on resin polymerization is unknown, and it could promote cooling of the resin mass, resulting in incomplete polymerization with high concentration of monomer, thus affecting the properties of the polymerized resin.

Another concern related to acrylic resin polymerization by a microwave procedure is its fracture strength, as little information is available about its failure modes, brittle fracture behavior and microstructure. ${ }^{1,7,8}$ Acrylic resin failure studies can be conducted by measuring impact strength and performing fracture resistance tests. ${ }^{7,9-11}$ However, to understand how and why fractures occur, it is necessary to analyze the morphology and microstructural behavior of a material ${ }^{5}$ under load application. The commonest analysis used is fractography, which describes the differences between fractures occurring in materials ${ }^{8,9,11}$ and allows the causes of failures to be identified and recognized.

With the advances observed in the proposed polymerization cycles to improve the laboratorial techniques, Vasconcellos et al. ${ }^{12}$ (2003) conducted a study in which they compared an alternative polym- erization cycle with that recommended by the manufacturer that includes a pause period. Their results showed that the transverse strength and surface microhardness were not affected by this alternative cycle, and porosity was lower compared with that found when the cycle recommended by the manufacturer was used.

Thus, the objective of this study was to evaluate accuracy of fit, impact strength, fracture morphology and microstructure of a microwave-polymerized resin, processed according to the manufacturer's instructions and to compare these results with those observed when an alternative polymerization cycle that excludes the pause period is used.

\section{Material and Methods}

Onda Cryl (Clássico Artigos Odontológicos Ltda., São Paulo, SP, Brazil) acrylic resin was used in this study. It is a microwave-polymerized polymethylmethacrylate denture base material. According to the manufacturer, the powder contains methylmethacrylate modified with ethylacrylate copolymer and a small percentage of benzyl peroxide. The liquid ingredients are methyl methacrylate monomer, topanol, and ethylene glycol dimethacrylate as the crosslinking agent.

For accuracy of fit, a metal master model of an edentulous maxilla was duplicated using a mold in vinyl polysiloxane (Aquasil ULV, Dentsply DeTrey, Konstanz, Germany) and dental stone type III (Herodent, Vigodent SA Ind. Com., Rio de Janeiro, RJ, Brazil) to fabricate 20 casts. The thickness of all denture bases was standardized by using $2 \mathrm{~mm}$-plastic sheets and the BIO-ART vacuum system (Plastivac P5, Bio-Art Equipamentos Odontológicos Ltda., São Carlos, SP, Brazil). The 20 plastic base/stone cast sets were randomly divided into two groups $(\mathrm{n}=10)$ and invested in flasks with dental stone type III. The manufacturer's directions for Onda Cryl manipulation were followed. The plastic flasks were placed in a microwave oven (Continental AW-42, with $2,450 \mathrm{~Hz}$ frequency and $900 \mathrm{~W}$ maximum power, Bosch Eletrodomésticos, Manaus, AM, Brazil) and assigned to the following cycles: MC (control group), according to the manufacturer's directions, $3 \mathrm{~min}$ at $360 \mathrm{~W}, 4-\mathrm{min}$ pause, and $3 \mathrm{~min}$ at $810 \mathrm{~W}$; 
and $\mathrm{AC}$ (experimental group), $6 \mathrm{~min}$ at $630 \mathrm{~W}$. After polymerization, all flasks were allowed to benchcool for 2 hours. The resulting acrylic resin bases were then removed, trimmed, and stored in 100\% relative humidity environment for 24 hours. After this period (T1) all specimens were measured for accuracy of fit and were then stored in distilled water at $37^{\circ} \mathrm{C}$ for 30 days, at which time they were again evaluated (T2).

Internal adaptation was evaluated by measuring a silicon film between the resin base and the metal master model. The internal surface of each resin base was coated with a flow type vinyl polysiloxane (Aquasil ULV, Dentsply DeTrey, Konstanz, Germany) and put onto the master cast under a $1.5 \mathrm{kgf}$ axial load. The resulting polymerized silicon film was trimmed at the borderline mark of the master cast and fit accuracy was then evaluated by measuring its thickness $(\mu \mathrm{m})$ at 3 points corresponding to the right $(\mathrm{A})$ and left $(\mathrm{B})$ ridge crests and the midline (C), all of them on the posterior palatal seal. Images from these points were captured by a digital color camera (Model SCC, Samsung, Seoul, Korea) connected to a stereoscopic microscope (Leica MZ 6, Heebrugg, Switzerland), at $12.5 \mathrm{X}$ magnification, and the measurements were made using Image Pro Plus 1.4 software (Media Cybernetics, Newburyport, Maryland, USA).

Impact strength was evaluated using rectangular acrylic resin specimens measuring $65 \times 10 \times 2.5 \mathrm{~mm}$. Metal master patterns were individually invested in high-viscosity silicone (Zetalabor, Zhermack S.p.A, Badia Polesine, Rovigo, Italy) and invested in Type III dental stone (Herodent Soli Rock, Vigodent SA Ind. Com., Rio de Janeiro, RJ, Brazil) within flasks (Onda Cryl, Artigos Odontológicos Clássico Ltd., São Paulo, SP, Brazil). ${ }^{13}$ Acrylic resin was mixed according to the manufacturer's instructions and packed into the silicone mold at the dough stage. All specimens were polymerized according to the cycles, MC $(\mathrm{n}=20)$ or AC $(\mathrm{n}=20)$.

After 2 hours of bench cooling, the specimens were deflasked, trimmed and finished using progressive abrasive papers (400-, 600- and 1,200grit, CARBIMET, Buehler, Lake Bluff, IL, USA) in a polishing machine (AROTEC, model APL-4, São
Paulo, SP, Brazil) and were stored in distilled water at $37 \pm 01^{\circ} \mathrm{C}$ for $48 \pm 02$ hours before testing. The impact strength test (Charpy method) was performed using an impact testing machine (Otto Wolpert Werke, Ludwighafen, Germany) with a $40 \mathrm{~kJ} /$ $\mathrm{cm}$ load and a $40 \mathrm{~mm}$-opening between the 2 fixed supports. ${ }^{7}$

Fractographic analysis was made for the 2 specimen fragments resulting from the impact test. Macroscopic analysis was performed by visual inspection of the fractured surfaces using a stereoscopic microscope (Leica MZ 6, Leica Geosystems, Heerbrugg, Switzerland) at $16 \mathrm{X}$ magnification. The fragments for each specimen were referred to as fragment A (FA) and fragment B (FB). During visual inspection, when FA and FB could be repositioned at the fractured line, presenting a smooth surface, the fractures were classified as brittle. ${ }^{7}$ Those presenting plastic deformation, exhibiting rough and jagged surfaces, were recorded as intermediate (ductile-to-brittle transition) fractures.

Quantitative analyses of the fractured segments and the angles of crack propagation generated in the direction of the applied load were performed. Each fragment was sectioned $5 \mathrm{~mm}$ from the border of the fracture, under water-cooling, with a precision saw (ISOMET 1000, Buehler, Lake Bluff, IL, USA) using a diamond-coated disc at $200 \mathrm{rpm}$. Images of both sides of the fractured specimens were recorded using a digital color camera (SCC 130A model, Samsung, Seoul, Korea) at a $40 \mathrm{X}$ magnification and analyzed by AutoCAD R14 software (Autodesk, Inc., San Rafael, CA, USA). The fractures were characterized according to the crack propagation angles from the fracture radius point of origin to each side of the fractured surface. These measurements were named Angle A and Angle B (Figure 1). An image of these angles was captured by the same method as previously described, and the angles were measured. The fracture morphology and the microstructure of all fragments were observed by scanning electron microscopy (LEO 435VP, Carl Zeiss SMT, Oberkochen, Germany).

Accuracy of fit data were submitted to ANOVA with multiple comparisons in the time considering a split plot design. The mean impact strength values 
were compared by the $t$ test and data from the fractographic analysis were submitted to the Wilcoxon Mann-Whitney test for angles, and the $t$ test for radius comparisons. The significant level was $5 \%$.

\section{Results}

Fit accuracy values for both groups (MC and AC) showed no significant differences. However, considering the storage time periods of $24 \mathrm{~h}$ and 30 days in water, significant differences were observed between times, and there was better adaptation after 30 days $(\mathrm{P}<0.05$, Table 1).

With regard to impact strength, no significant differences were found between the cycles: $\mathrm{MC}=0.23(0.03) \mathrm{J}$, and $\mathrm{AC}=0.22(0.03) \mathrm{J}(\mathrm{P}=0.47)$. Visual inspection revealed that most fractures were

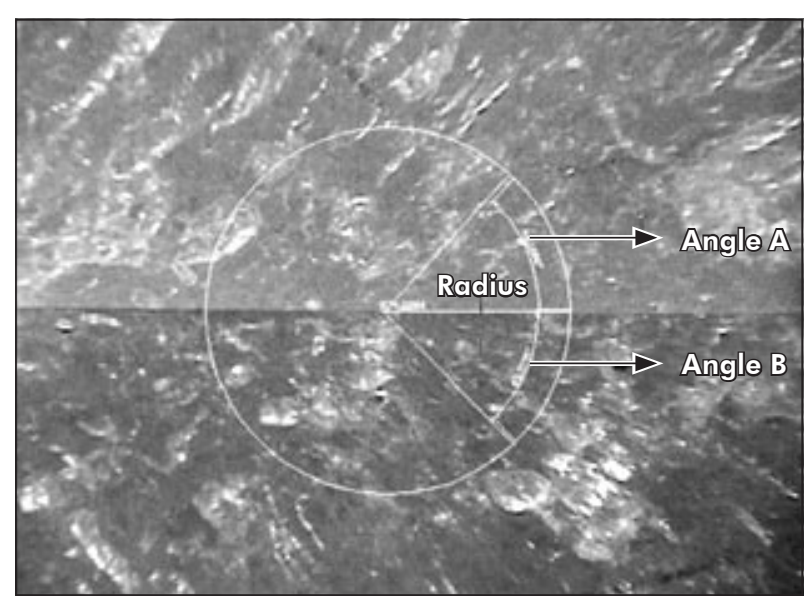

Figure 1 - Angular analysis of 2 fragments of Onda Cryl after impact test. Angles A and B represent crack propagation angles from fracture point of origin at the junction of the 2 fragments resulting from the impact test.

Table 1 - Accuracy of fit evaluated by the thickness $(\mu \mathrm{m})$ of the impression material at each point after $24 \mathrm{~h}$ and 30 days of water storage. Means (SD).

\begin{tabular}{|c|c|c|c|}
\hline Cycles & Point & T1 - After 24 hours & T2 - After 30 days \\
\hline$M C$ & \multirow{2}{*}{ A } & $71.0(9.2)^{a}$ & $59.8(6.5)^{b}$ \\
\hline$A C$ & & $69.8(9.2)^{\circ}$ & $58.6(8.1)^{b}$ \\
\hline$M C$ & \multirow{2}{*}{ B } & $76.9(10.4)^{a}$ & $66.9(10.5)^{\mathrm{b}}$ \\
\hline$A C$ & & $78.7(10.1)^{a}$ & $69.2(7.9)^{\mathrm{b}}$ \\
\hline$M C$ & \multirow{2}{*}{ C } & $65.1(5.6)^{a}$ & $54.4(6.1)^{b}$ \\
\hline$A C$ & & $68.6(7.5)^{\mathrm{a}}$ & $58.0(9.2)^{\mathrm{b}}$ \\
\hline
\end{tabular}

Mean values followed by distinct letters differ significantly $(p<0.05)$. brittle. In the $\mathrm{MC}$ group $70 \%$, and in the $\mathrm{AC}$ group $80 \%$ of the specimens showed brittle fractures. SEM microphotographs showed the same surface pattern for brittle (Figures 2, A-B) and intermediate (Figures 2, C-D) fractures for both polymerization cycles.

The median values for Angle A, Angle B and the Radius for brittle fractures were $\mathrm{MC}=45.9^{\circ}, 46.1^{\circ}$, $72.0 \mu \mathrm{m} ; \mathrm{AC}=44.5^{\circ}, 46.2^{\circ}, 72.1 \mu \mathrm{m}$, and for intermediate fractures, $\mathrm{MC}=58.9^{\circ}, 57.2^{\circ}, 71.2 \mu \mathrm{m}$; $\mathrm{AC}=59.5^{\circ}, 59.8^{\circ}, 72.1 \mu \mathrm{m}$. No significant differences were found between $\mathrm{MC}$ and $\mathrm{AC}$ in the two types of fractures $(\mathrm{p}<0.05)$.

\section{Discussion}

The adaptation of dentures can be affected by polymerization cycles or water sorption, resulting in dimensional changes capable of altering the structural integrity, developing cracks and predicting fractures by impact or chewing forces..$^{14}$ Identifying the distortions and the origin of stress absorption in the acrylic resin of the denture base, and its effects on the microstructure, may contribute to understanding the material failure ${ }^{7}$ before any damage to oral tissues is done.

In the present study, comparisons between polymerization cycles showed no significant differences for accuracy of fit in the two cycles studied (Table 1). This result indicated that exclusion of the pause period did not influence the acrylic resin polymerization or cause any distortion of the denture base. This result favors the alternative cycle, in which the constant heating for 6 minutes at $630 \mathrm{~W}$ did not promote any change in the exothermic peak during the polymerization that could negatively affect fit accuracy. However, as was expected, storing the denture base resin in water for 30 days increased fit accuracy $(\mathrm{p}<0.05)$ irrespective of the polymerization cycle used (Table 1). These findings are in agreement with those of previous studies that showed that acrylic resin polymerization shrinkage was compensated by water storage, resulting in better fit. ${ }^{3,5,6}$ Cross linking agents, such as ethylene glycol dimethacrylate, ${ }^{15}$ and the acrylic resin denture base thickness ${ }^{16}$ are also related to the magnitude of shrinkage during polymerization, thus affecting the dimensional expansion by water sorption. 

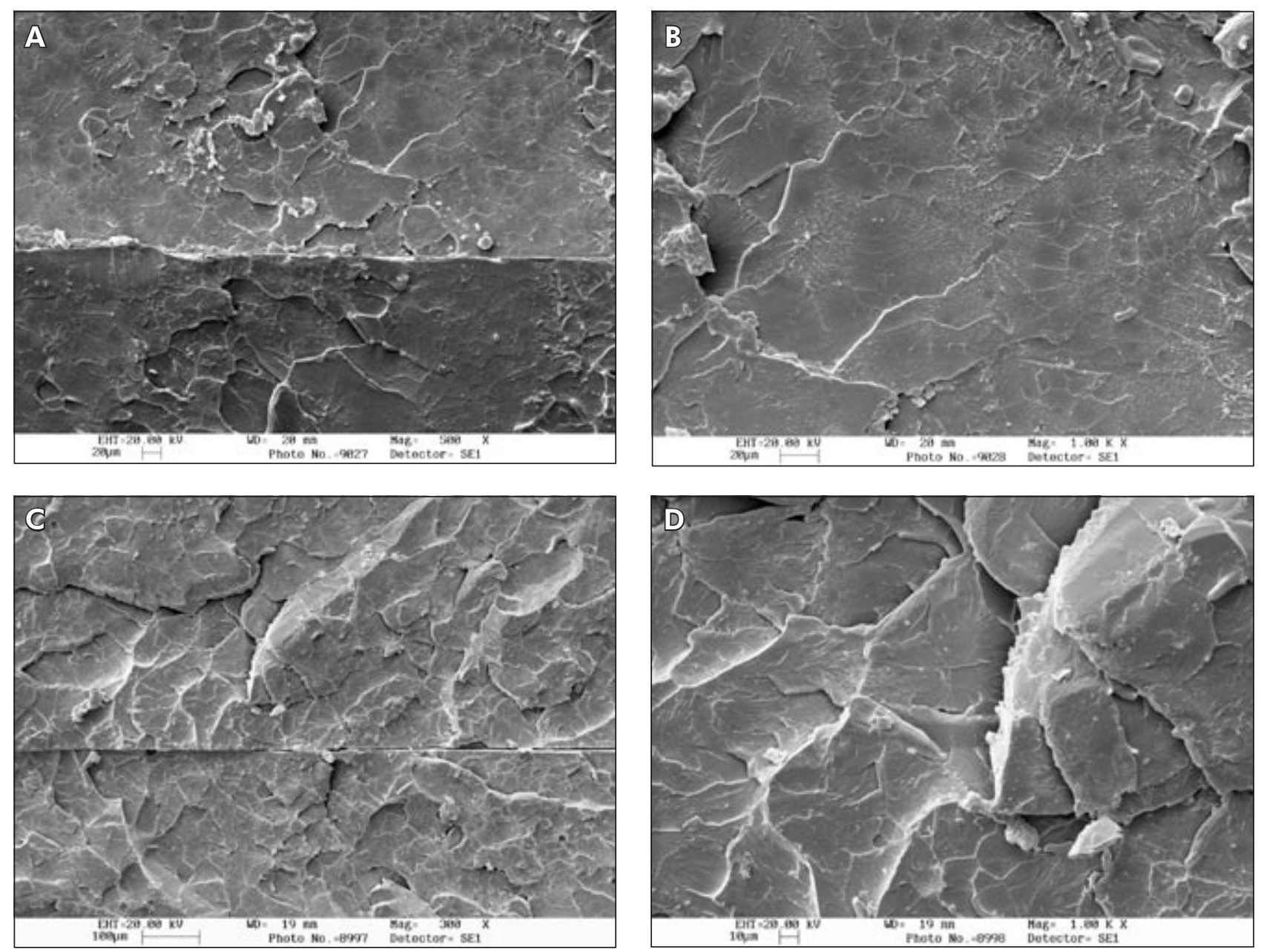

Figure 2 - A and B, SEM of brittle fractures showing plane, compact and organized surface. C and D, SEM of intermediate fractures showing an irregular and disorganized surface with typical stepped regions.

With regard to impact strength, the results showed no differences between polymerization cycles and they were close to those described by Faot et al. ${ }^{7}$ (2006) for acrylic resins processed by microwave energy. The acrylic resins processed by $\mathrm{MC}$ and AC probably present the same inter-chain force and crosslinked polymeric chain arrangements, which equally absorb the stress during fracture.

The macroscopic fractographic analysis results showed similar percentages of brittle fractures $(\mathrm{MC}=70 \% ; \mathrm{AC}=80 \%)$ and intermediate fractures $(\mathrm{MC}=30 \% ; \mathrm{AC}=20 \%)$ for both groups. This result is in agreement with the surface characteristics of polymer fractures which, irrespective of the addition of cross linking agents, do not exhibit exclusively brittle behavior. ${ }^{9,17}$ The brittleness can also be explained by the impact tests having been carried out at a high speed, which may influence the deformation mechanism in acrylic resin, and the crack initiation and propagation behavior. ${ }^{9,11,18}$ Therefore, the advantages of the impact strength test are its simplicity and allowing the intrinsic properties of fractured material to be analyzed by determining the crack propagation angles. ${ }^{9,18}$

The fractographic analysis of the angles showed no significant differences for the two polymerization cycles. The fracture types, and the angular values were obtained in accordance with the principles of fractography in polymers. ${ }^{9,11}$ In addition, analysis of the fractured surfaces by scanning electron microscopy (Figure 2) demonstrated no differences between the crystallographic plane configurations of 
the brittle (Figure 2, A-B) and intermediate fractures (Figure 2, C-D) in the two polymerization cycles. A granular microstructure was clearly distinguishable, demonstrating that the acrylic resin fails exclusively by transgranular or transcrystalline fracture. ${ }^{8,9}$ The presence of intermediate fractures in brittle materials can be explained by many factors, such as poor design, faulty processing, unexpectedly severe service conditions, or a combination of these. ${ }^{18}$

Stress dissipation in the acrylic resins of denture bases can occur as a result of microstructure problems or alterations originated by the processing technique, such as alteration of the microwave oven time and power, for example. Fracture studies are important, and using a stereoscopic microscope is an easy and simple technique that allows the crack propagation plane to be identified. The angles de-

\section{References}

1. Azzari MJ, Cortizo MS, Alessandrini JL. Effect of curing conditions on the properties of an acrylic denture base resin microwave-polymerized. J Dent. 2003;31(7):463-8.

2. Blagojevic V, Murphy EVM. Microwave polymerization of denture base materials. A comparative study. J Oral Rehabil. 1999;26(10):804-8.

3. Hugget R, Brooks SC, Bates JF. The effect of different curing cycles on the dimensional accuracy of acrylic resin denture base materials. Quintessence Dent Technol. 1984;8(2):81-5.

4. Lai CP, Tsai MH, Chen M, Chang HS, Tay HH. Morphology and properties of denture acrylic resins cured by microwave energy and conventional water bath. Dent Mater. 2004;20(2):133-41.

5. Sanders JL, Levin B, Reitz PV. Comparison of the adaptation of acrylic resin cured by microwave energy and conventional water bath. Quintessence Int. 1991;22(3):181-6.

6. Teraoka F, Takahashi J. Controlled polymerization system for fabricating precise dentures. J Prosthet Dent. 2000;83(5):51420.

7. Faot F, Almeida M, Del Bel Cury AA, Rodrigues Garcia RC. Impact strength and fracture morphology of denture acrylic resins. J Prosthet Dent. 2006;96(5):367-73.

8. Kusy RP, Turner DT. Fractography of poly(methyl methacrylates). J Biomed Mater Res. 1975;9(4):89-98.

9. Callister Jr WD. Material Science and engineering: an introduction. $7^{\text {th }}$ ed. Hoboken (NJ): John Wiley \& Sons; 2006. p. 232-4; 524-33. scribed for each fracture pattern can then be used for studying the fracture behavior of acrylic resin.

The results suggest that this acrylic resin did not suffer any process of thermal fatigue during the polymerization by the alternative cycle $(630 \mathrm{~W}-6 \mathrm{~min}-$ utes). In addition, considering the results found by Vasconcelos et al. ${ }^{12}$ (2003), the alternative polymerization cycle could be incorporated to laboratory routines, producing denture resin with the same quality of that polymerized according to the manufacturer's directions.

\section{Conclusions}

Within the limitations of this in vitro study, eliminating the pause period during the polymerization cycle did not alter the properties of the microwave acrylic resin studied.

10. Hertzberg RW. Deformation and fracture mechanics of engineering materials. $4^{\text {th }}$ ed. New York: JW. Inc.; 1996. p. 211-53; 279-303.

11. Mecholsky Jr JJ. Fractography: Determining the sites of fracture initiation. Dent Mater. 1995;11(2):113-6.

12. Vasconcelos L, Feitosa MAL, Del Bel Cury AA, Rodrigues Garcia RCM. Avaliação de um ciclo alternativo de polimerização para a resina acrílica de microondas. RPG Rev Pós Grad. 2003;10:108-11.

13. Del Bel Cury AA, Rached RN, Ganzarolli SM. Microwavecured acrylic resins and silicone-gypsum molding technique. J Oral Rehabil. 2001;28(5):433-8.

14. Beyli MS, Von Fraunhofer JA. An analysis of causes of fracture of acrylic resins. J Prosthet Dent. 1981;46(3):238-41.

15. Arima T, Murata H, Hamada T. The effects of cross-linking agents on the water sorption and solubility characteristics of denture base resin. J Oral Rehabil. 1996;23(7):476-80.

16. Sadamori S, Ishii T, Hamada T. Influence of thickness on the linear dimensional change, warpage, and water uptake of a denture base resin. Int J Prosthodont. 1997;10(1):35-43.

17. Memon MS, Yunus N, Razak AA. Some mechanical properties of a highly cross-linked, microwave-polymerized, injection-molded denture base polymer. Int J Prosthodont. 2001;14(3):214-8.

18. Nimmer R. Impact loading. In: Reinhart TJ, editor. Engineered materials handbook. Metals Park $(\mathrm{OH})$ : ASM International; 1988. p. 554-740. 